\title{
LIII. A new mode of making magic mirrors
}

\section{J. W. Kearton}

To cite this article: J. W. Kearton (1894) LIII. A new mode of making magic mirrors, Philosophical Magazine Series 5, 37:229, 546-548, DOI: 10.1080/14786449408620589

To link to this article: http://dx.doi.org/10.1080/14786449408620589

曲 Published online: 08 May 2009.

Submit your article to this journal 중

Q View related articles $₫$ 


\section{$\left[\begin{array}{lll}546 & ]\end{array}\right.$ \\ LIII. A New Mode of making Magic Mirrors. By J. W. Kearton*.}

THE first explanation that occurred to me on seeing the 1 Japanese mirror about fourteen months ago was that the face might bear directly invisible differences in polish, which a powerful beam of light would probably convert into visible ones by reflexion on to the screen. To produce such minute differences, it was my intention to take pairs of different metals closely agreeing in colour and reflective power, as silver and platinum, and to deposit electrically in the form of some easily recognizable figure a thin coating of the one metal on a groundwork of the other. Very faint mercuric staining of bright metallic surfaces was also contemplated. These ideas, however, resolved themselves into a test much simpler, yet involving the same principle. A piece of metal was so polished that in subdued daylight a cross, more finely burnished than the general surface of the plate, could just be distinguished. Reflected on to the screen, the figure came out exceedingly faint; and this fact, apart from the consideration that figures so produced could have only a precarious existence, was sufficient to condemn the hypothesis in question.

This result has a bearing upon another hypothesis-one worthy of prompt burial with the quiddities and essences of the purely deductive method, viz., that the magic-mirror phenomena are due to local molecular rearrangements in the reflecting surface, brought about by unequal cooling of the mass of the mirror. Now, since it is held that the regularity or convexity of the surface is not thereby affected, this molecular rearrangement can put itself in evidence optically only by refiecting more or less light than the parts of the surface unaffected by irregular cooling. But it has been shown that with figures so pronounced as to be directly visible, the electric beam is powerless to produce results comparable in intensity with those given by the Japanese mirror; much less will directly invisible figures of the type under reference come up to the required standard.

The plate used in the foregoing experiment, whilst furnishing no clue in virtue of its polished figure, yet presented evidence that pointed clearly in the direction where a solution of the problem was to be found. Strikingly well-defined lines and dapplings of light were thrown on the screen by

* Communicated by the Physical Society : read January 26, 1894. 
light reflected from the disk. These marks were found to correspond to concave strains produced by hammering the plate into rough convexity before scouring down with charcoal. Depressions produced by electro-deposition of silver on a silvered plate, protected in parts by varnish according to the figure desired, were therefore tried ; but they invariably deepened into the underlying brass before the sharp edges of the figure were polished away.

Next, a fairly thick coating of silver was deposited on the plate, and a pointed bit of agate was repeatedly drawn with pressure over certain parts of the porous layer of metal. The figures thus obtained were startling ; for the depressions appeared on the screen as reticulated lines of deep shade, which had their analogue in the broken spinal divisions left by the agate point. The bad working of metals electrically deposited caused me to give up the deposition method.

My plate of brass was next slung up in a weak solution of copper sulphate and sulphuric acid on the positive wire of a pint bichromate-cell. After an immersion of four minutes, the parts of the plate not protected by the naphthaline solution of sealing-wax came out beautifully fretted. After several attempts on these lines, and two diays after the lecture delivered here by Prof. S. P. Thompson on the 27th of January last on the Magic Mirror, my first success was achieved in the shape of a mirror 2 inches in diameter, representing a stem with leaves and a guide-post standing in a mound of earth. From that mirror to my present one, the first of the new class being completed in the following July, was, however, a far cry. Applied to larger mirrors and figures, the electrical method proved essentially bad. Exactly contrary to what was required, the figures were deeper at the edges of the lines than at the central parts : indeed, a broad line scoured down into two lines defining the lateral limits of the original one.

Nitric acid was finally adopted as the figure-eating agent, care being taken to use good brass and to polish well before immersion, so that the action on the plate might be uniform. Smooth figures were thus produced after immersions of upwards of six seconds in strong acid. The walls of the figures are perpendicular to the surface of the disk, and the determination of their proper height relatively to the breadth of the lines of the figure involved much further labour. The process of scouring with Sheffield lime and swans'-down calico has a double effect-it rounds off the upper rectangular edges of the walls, and at the same time converts the flat floors of the figure into concave depressions, the walls and 
floors finally merging into one concave sweep. This curve, with narrow lines, is sharper than with broad lines; consequently the latter may disappear, while the former remain visible. Very brief immersions in the acid are therefore not suitable for figures having lines differing much in breadth. Long immersions, on the other hand, are objectionable both on the ground of the excessive labour in rounding off the edges, and of the well-nigh impossible task of reducing uniformly the deep runnels of the figure by scouring the general surface with charcoal.

Gradations in depth according to the breadth of the several limbs were therefore tried, and produced in the following way :--The figure, say of a tree, is made by removing paraffin wax from the brass plate with a pointed stick of boxwood, and is then fixed by a very short immersion in the acid. The slender branches are now painted over with hot wax, and the broader branches and trunk are reduced in breadth symmetrically by the same means, the plate then being immersed a second time. By a repetition of alternate painting and immersing, all the members of the figure are made to increase in depth by fine gradations from the boundary lines to the central parts. This method, specially applicable to figures with very broad and narrow lines, is, however, rather troublesome, and does not give satisfactory results unless the gradations are minute, which otherwise will be brought out by reflexion on to the screen.

Reverting to single immersions, final experiments were made with plates bearing figures prepared in the usual way, viz. by removal of wax, a record being kept of the strength of the acid and the time of immersion in each case. The result is that for figures with lines ranging from $\frac{1}{16}$ to $\frac{3}{8}$ of an inch in breadth, an immersion of 3 seconds in a solution of 5 volumes of concentrated nitric acid to 2 of water gives a satisfactory depth.

The next step was to produce figures in low relief, which come out on the screen in shade. As there is in this case no intersection of the reflected rays, and, consequently, no blotting out or dimming of the figures, very narrow lines may be used. These are conveniently drawn with a camel's-hair brush and sealing-wax dissolved in naphtha. From 1 to 2 seconds' immersion, according to the breadth of the characters, will be found sufficient. 